\title{
EFEITO DA DESSECAÇÃO DAS FEZES DE TRIATOMÍNEOS NA SOBREVIVÊNCIA DE FORMAS METACÍCLICAS DE TRYPANOSOMA CRUZI
}

\author{
Vânia A. Soares 1 , Philip D. Marsden 1 e Colin Johnson 2
}

\begin{abstract}
Estudou-se a taxa de dessecação das fezes de triatomineos à temperatura ambiente e diferentes umidades relativas e à temperatura média da pele humana $\left(33^{\circ} \mathrm{C}\right)$.

O tempo necessário para evaporar a água contida nas fezes de barbeiro é inversamente proporcional ao déficit de saturação atmosférica e é acelerado a temperaturas mais altas.

Estudou-se a motilidade dos flagelados fecais diretamente ao microscópio e a infectividade dos mesmos após introdução na cavidade peritoneal de camundongos.

A baixa umidade ambas, motilidade e infectividade, foram perdidas antes de 30 minutos. Em altas umidades esses parâmetros foram preservados, em grau variado, por mais de 30 minutos. $\mathrm{A} 33^{\circ} \mathrm{C}, 100 \%$ dos camundongos foram infectados depois de 15 minutos, mas somente $3,3 \%$ após 30 minutos de exposição.

As condiçoes ambientais no interior de uma casa em Mambai variaram acentuadamente no periodo de estudo. Entretanto, foram geralmente similares àqueles observados experimentalmente em laboratório.
\end{abstract}

Palavras chaves: Dessecação. Microclima de pele. Doença de Chagas.

Chagas $^{3}$ afirmava que as fezes de triatomideos, quando expostas ao ambiente, sofreriam rápida dessecação com conseqüente morte das formas infectantes do Trypanosoma cruzi. Marsden ${ }^{5}$ ressalta entre outros fatores relacionados ao risco de infecção aquele ligado ao microclima da pele humana. Realmente a determinação da ocorrência ou não da infeç̧ão chagásica começa a ser estabelecida na interfase peleambiente e a dessecação do material fecal, depositado sobre o tegumento, determinará o tempo que as formas infectantes do $T$. cruzi terão para encontrar uma porta de entrada e estabelecer a infecção. Portanto, a dessecação é fator limitante para a sobrevivência de formas metacíclicas do $T$. cruzi. Mas, apesar de importante não foi estabelecido, até o momento, a sobrevivência e a viabilidade dessas formas em condições ambientais controladas. Portanto, os experimentos aqui descritos abre um campo ainda inexplorado e importante na transmissão da doença de Chagas.

Esse trabalho tem como objetivo determinar, através de modelo experimental, o tempo de sobrevivència e a viabilidade das formas de $T$. cruzi, proveniente de fezes de triatomineos em condições de umidade relativa e temperatura controladas.

\section{MATERIAL E MÉTODOS}

$\mathrm{Na}$ realização dos experimentos utilizaram-se nos testes de infecção, camundongos albinos, ma-

\footnotetext{
1. Núcleo de Medicina Tropical e Nutrição/Universidade de Brasilia.

2. Departamento de Biologia Vegetal/Universidade de Brasilia.

Recebido para publicação em 29/10/85
}

chos, com um mês de idade e ninfas de Dipetalogaster maximus (Uhler, 1984), para obtenção das fezes e para o xenodiagnóstico (quando necessário comprovar a negatividade dos camundongos). Trabalhou-se com a cepa luiu de $T$. cruzi, cuja amostra foi isolada de triatomíneo naturalmente infectado, capturado em habitat doméstico na Baix ada do Iuiu, Bahia em 1974, que apresenta grande número de metaciclicos.

Os experimentos foram realizados em duas etapas: 1) Em câmara com umidade relativa controlada e à temperatura ambiente; e 2) $\grave{A}$ temperatura media da pele humana ${ }^{7}\left(3^{\circ} \mathrm{C}\right)$ e umidade relativa ambiental.

Etapa 1 - Nesta etapa utilizaram-se quatro càmaras com as seguintes umidades relativas: $90 \% \pm 2$, $60 \% \pm 2,45 \% \pm 5$ e $25 \% \pm 5$. Para checagem e calibração das câmaras nos niveis de umidade desejados utilizou-se psicrômetro miniaturizado constituído por termopar; a umidade foi calculada pela Equação de Regnault ${ }^{6}$.

Primeiramente determinou-se a dessecação das fezes para cada umidade considerada.

As fezes foram obtidas de ninfas de 5 ? estádio de D. maximus; essas ninfas foram alimentadas em camundongos normais. Após o repasto, introduziuse a metade posterior do corpo das ninfas em frascos de vidro, imobilizando-as com fita crepe ${ }^{9}$. Os frascos com as ninfas foram, então, colocadas no interior de câmara úmida e aguardou-se a defecaçào espontânea. A urina eliminada com as fezes foi o diluente. Após a coleta das fezes, $0,01 \mathrm{ml}$ foi distribuido, com auxilio de uma seringa micrométrica sobre uma área circular com $0,5 \mathrm{~cm}$ de diâmetro delimitada em confetes plásticos; pesou-se o 
material a fresco. Um lote de cinco confetes foi colocado em cada câmara e a cada cinco minutos foram retirados e pesados. $O$ processo de exposição às câmaras seguido de pesagem foi repetido sucessivamente até a dessecação total do material, atingida quando não se observa alteração entre as passagens de dois ciclos consecutivos. Fez-se, então, o teste de motilidade das formas de $T$. cruzi. O processo foi semelhante ao anterior sendo que 15 confetes, contendo o mesmo volume de fezes com formas móveis de $T$. cruzi, foram colocados em cada câmara e, entāo, observou-se ao microscópio a presença de formas móveis. Quando não se encontrava, retirava-se outro confete, só se considerando todas as formas mortas quando todos os confetes fossem negativos. Após esse teste, partiu-se para os testes de infecção. Recolhidas as fezes, como acima descrito estimou-se o numero de metacíclicos na amostra ${ }^{2}$. As fezes com número conhecido de metacíclicos foram distribuídas nos mesmos confetes plásticos de modo a preencher a área delimitada nos mesmos. Os confetes foram, então, colocados nas câmaras, aí permanecendo por 30 minutos. Findo esse tempo os confetes foram introduzidos na cavidade abdominal de camundongos anestesiados, por incisão feita previamente que, então, foi suturada com pontos metálicos especiais (Michel clips). Cuidava-se para não atingir as vísceras dos animais.

No total foram utilizados 119 animais, sendo 25 para os materiais mantidos a $25 \%$ e 25 a $45 \%$ de umidade relativa, 30 para os mantidos a $60 \%$ e 39 para os mantidos a $90 \%$ de umidade relativa. Os animais foram examinados diariamente para verificação de reação inflamatória no local da incisão. Além dos animais do grupo de teste, dois grupos-controles foram utilizados: um deles com 21 animais recebeu inóculo intraperitoneal de $0,1 \mathrm{ml}$ do mesmo conteúdo fecal utilizado nos testes e outro com 18 animais recebeu um confete livre de material infectante na cavidade abdominal. Os camundongos que receberam inóculo intraperitoneal de fezes foram examinados aos 14,21 e 28 dias. De acordo com Alvarenga e Marsden ${ }^{1}$ $95 \%$ dos animais manifestam infecção nesse periodo. Além do exame direto procedeu-se o xenodiagnóstico nos animais que não apresentaram parasitemia patente e o teste do desafio naqueles que continuaram negativos pelo xenodiagnóstico. A técnica do desafio consta de inóculo de formas sangüineas de cepa virulenta de $T$. cruzi em doses que são normalmente letais para camundongos normais. A sobrevivência dos animais sugeriria que eles teriam se tornado imunes, graças a infecção não patente produzida pelo primeiro inóculol. Para esse teste utilizou-se cepa Y de $T$. cruzi em inóculo intraperitoneal; um grupo controle foi também inoculado. $O$ exame desses animais foi realizado aos 7,14 e 21 dias após o desafio.
Etapa 2 - Essa parte do experimento foi realizada à temperatura da pele humana, $33^{\circ} \mathrm{C}$ e à umidade relativa ambiente. Para regular a temperatura ao nivel desejado utilizou-se um aparelho constituido por um suporte de madeira que sustentava uma placa de aluminio pintada de preto (absorve mais calor) onde acoplou-se um termostato eletrônico. A fonte de radiação foi uma lâmpada de 100 watts, a temperatura foi medida por um termômetro eletrônico de Gossen. Como na etapa anterior, a dessecação foi avaliada pela alteração do peso do material fecal com o tempo. Primeiramente, construiram-se as curvas de dessecação de modo semelhante ao descrito anteriormente, o mesmo volume de fezes foi depositado sobre dez confetes plásticos, que foram, então, distribuidos sobre a placa a $33^{\circ} \mathrm{C}$. A cada cinco minutos pesava-se os confetes repetindo-se o procedimento até a dessecação total do material. Fez-se, também, o teste de motilidade das formas, como na etapa anterior, expondo o confete à placa e a cada cinco minutos observava-se a presença de formas móveis na amostra.

Baseado nos resultados do teste de motilidade $e$ na curva de dessecação a temperatura controlada, estipulou-se o tempo de 15 e 30 minutos de exposição das fezes às condições acima descritas para a realizaçăo dos testes de infecção. Portanto, após cada periodo de exposição confetes eram introduzidos no interior da cavidade abdominal dos camundongos, sendo 30 animais em cada lote e mais 15 controles, que receberam inóculo de $0,1 \mathrm{ml}$ do mesmo conteúdo fecal, intraperitonealmente. Os exames para observação da parasitemia foram realizados seguindo padrão já descrito.

Para análise estatistica dos resultados utilizouse o Teste de diferença entre duas proporções para $\propto=0,05$ e considerou-se somente os animais vivos quando do primeiro exame.

Além dos experimentos de laboratório, medidas de umidade relativa e temperatura máxima e minima diárias foram registradas durante 16 meses no interior de uma habitação típica de área endèmica da doença de Chagas, situada em Mambai - Góias (140 $28^{\prime} 48^{\prime \prime}$ de latitude sul e $46^{\circ} 06^{\prime} 00^{\prime \prime}$ de longitude oeste) a $332 \mathrm{~km}$ de Brasília, com a finalidade de conhecer a variação dessas medidas, que quando complementadas com os testes de laboratório contribuiram para esclarecer o processo de dessecação no ambiente natural da infecção.

$\mathrm{Na}$ determinação da umidade relativa utilizou-se psicrômetro não ventilado. As medidas foram tomadas às 7:00, 13:00 e 19:00 horas diariamente, de setembro de 1980 a dezembro de 1981 , registrando-se também as temperaturas máxima e mínima diárias.

\section{RESULTADOS}

A variação da taxa do peso relativo das fezes de triatomineos em relação ao tempo é diferente para 
cada nivel de umidade relativa considerada, como pode ser observada na Figura 1 . A inclinaçào da curva é menos acentuada para altos niveis da mesma, já que a água presente nas fezes é mais rapidamente evaporada a niveis de umidade mais baixos e à mesma temperatura.

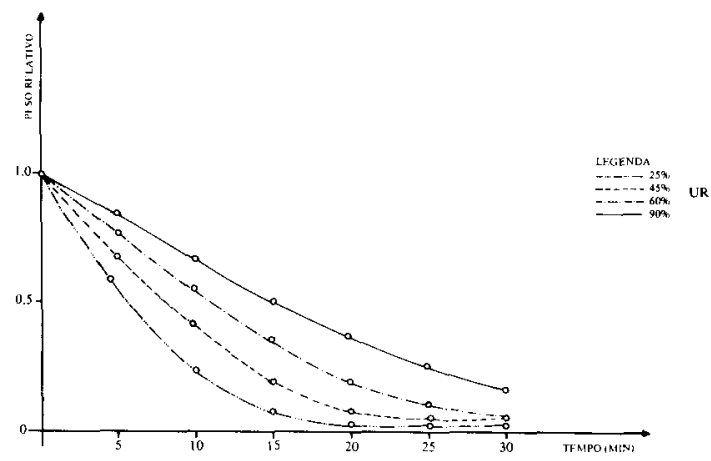

Fig. 1 - Curvas de dessecação para câmaras com umidade relativa controlada è temperatura ambiente.

A Figura 2 mostra o periodo necessário para que $95 \%$ de água presente nas fezes evapore, que é inversamente proporcional ao déficit de vapor d'água no $\operatorname{ar}(\delta \mathrm{e})$. Quanto maior for esse déficit maior o efeito da dessecaçào sobre as formas metacíclicas do T. cruzi expostas ao ambiente, portanto menor a sobrevida do flagelado.

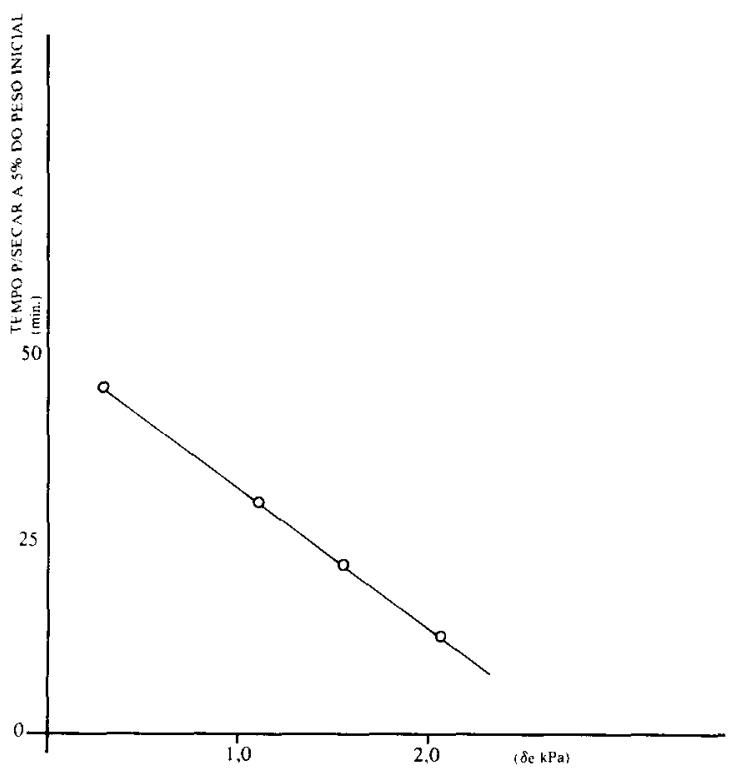

Fig. 2 - Periodo para secar a 5\% o material fecal em função ao déficit de saturação $(\delta \mathrm{e})$.

- Ponto referente a $33^{\circ} \mathrm{C}$ e UR de $73 \%$.

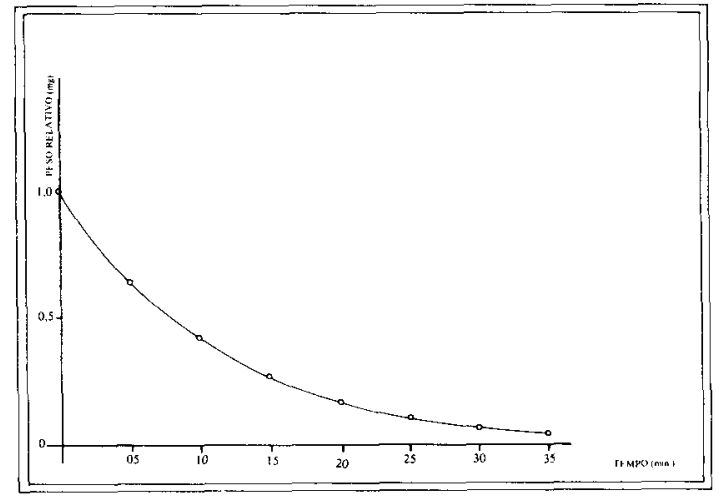

Fig. 3 - Curva de dessecação à temperatura de $33^{\circ} \mathrm{C}$ e umidade relativa ambiental (73\%).

A Figura 3 corresponde à curva de dessecaçāo para temperatura de $33^{\circ} \mathrm{e}$ umidade de $73 \%$ e mostra a variação do peso relativo com o tempo.

A Tabela 1 mostra os resultados comparativos dos testes de infecção, motilidade e tempo necessário

Tabela 1 -Resultados de dessecação, motilidade e infecção em ambientes com umidade relativa controlada è temperatura da pele e $73 \%$ de umidade relativa.

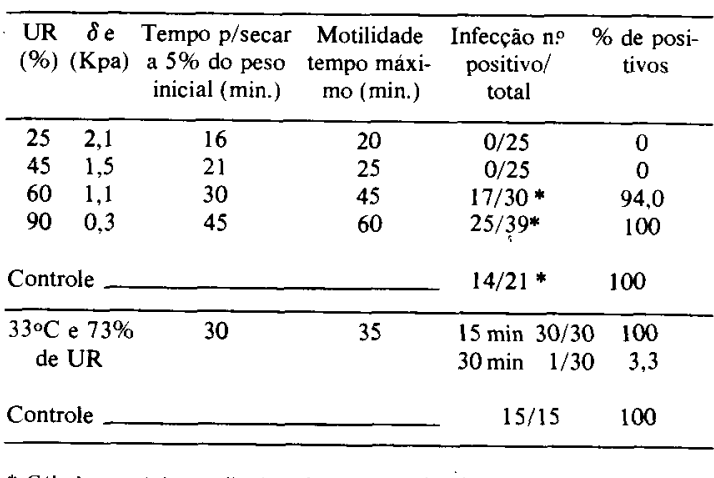

* Calculos estatisticos realizados sobre o número de animais vivos no primeiro exame.

para as fezes atingirem $5 \%$ do peso inicial em duas condições, primeiro para 30 minutos de exposição à câmara com umidade relativa controlada e a temperatura ambiente e, segundo, para 15 e 30 minutos de exposição à temperatura de $33^{\circ} \mathrm{C}$ e umidade relativa ambiente (73\%).

Não se observou diferença significante $\left(\mathrm{P}_{1}=\mathrm{P}_{2}\right)$ nas taxas de infecção dos materiais mantidos a 60 a $90 \%$ de UR por 30 minutos. Quanto ao material mantido a $33^{\circ} \mathrm{C}$ (UR: $73 \%$ ), observou-se diferença significante nas taxas de infecção dos animais que receberam fezes mantidas por 15 e 30 minutos sob essas condiçōes.

Quanto aos indices de umidade relativa no interior da habitação estudada, baseada em médias 
quinzenais, apresentaram padrão caracteristico, sendo seis meses de seca e seis meses chuvosos e variaram acentuadamente tanto durante $o$ ano quanto durante $o$ decorrer de um mesmo dia. Os niveis mais altos de UR foram observados nos meses de novembro, dezembro, janeiro e fevereiro, correspondendo à média de $85 \%$ e os meses mais secos foram julho, agosto e setembro, sendo que os periodos que apresentaram valores mais altos correspondiam àqueles da manhã $(7: 00 \mathrm{~h})$ e os mais baixos à tarde (13:00 h).

Quanto às médias de temperaturas máximas, atingiram valores mais altos na segunda quinzena de outubro de 1980 , sendo igual a $31,6^{\circ} \mathrm{C}$ e o valor mais baixo em junho do mesmo ano foi $24^{\circ} \mathrm{C}$. Em relação à média das temperaturas minimas, foram mais altas na primeira quinzena de março de 1981 , sendo $25^{\circ} \mathrm{C}$ a mais baixa na segunda quinzena de julho e foi de $16^{\circ} \mathrm{C}$. A amplitude térmica foi maior na segunda quinzena de outubro de 1980 e nos meses de maio e setembro de 1981, correspondendo à época mais seca.

\section{DISCUSSĀO}

A avaliação da dessecação através da redução do peso do material fecal com o tempo, mostrou-se eficiente, podendo contribuir como primeira indicação do problema de infecção pelo parasito, relacionando-o com condiçōes do ambiente do hospedeiro. Essa eficiència é comprovada quando se observa a Tabela 1. As divergências observadas podem ser explicadas pela deformação na escala da curva, já que as estimativas do período para que $95 \%$ da água evaporasse foram retiradas diretamente das curvas de dessecação. A escolha desse periodo deveu-se ao fato de que o peso do material fecal seco corresponde a aproximadamente $5,5 \%$ do peso do material fresco, além das pequenas variações acrescentadas pelas repetições do experimento.

Quando se observa as curvas de dessecação a cada nivel de UR considerado, nota-se que dois fenómenos distintos parecem ocorrer. (Fig. 1). No inicio do periodo de exposição (até $\pm 15 \mathrm{~min}$ ) as curvas são aproximadamente lineares. Após um ponto critico, diferente para cada umidade, o padrão se modifica talvez devido a formação de uma crosta na superfície da gota de fezes, que alteraria o fluxo de evaporação.

Quando se considera a temperatura de $33^{\circ} \mathrm{C}$, observa-se que a motilidade é perdida rapidamente, quanto a dessecação e mais lenta do que se esperaria para o déficit de saturação considerado $(2,8 \mathrm{Kpa})$ como se observa na Figura 2 e Tabela 1. Seria necessário aperfeiçoar o modelo no sentido de poder estudar o efeito da dessecação a vários niveis de umidade relativa e a temperatura da pele o que se aproximaria mais da realidade.
Para se ter idéia mais concreta do risco da infecção no interior de uma habitação típica de área endêmica tomou-se medidas de umidade relativa $e$ temperatura máxima e minima diárias, observou-se que a UR é bastante variável tanto ao longo do dia quanto nos diversos meses do ano, devido, talvez, ao material usado na construção ser muito higrofilico ( $\mathrm{R}$ Mossé: comunicação pessoal) ou ainda pelo fato das casas serem construidas diretamente sobre o soloe raramente possuir assoalho; aliada à má ventilação dessas habitações improvisadas, deve-se considerar, ainda, o hábito das pessoas residentes de molhar o chão devido a poeira, contribuindo, assim, para a variação de umidade observada.

A temperatura no interior da habitação não variou tão acentuadamente quanto a UR, isso possivelmente devido a capacidade de isolamento térmico do material de construção.

Ao considerar-se os dados de campo e comparálos com os resultados obtidos experimentalmente em laboratório, observa-se que há meses (novembro, dezembro, janeiro e março) em que a umidade relativa atinge niveis altos (70-90\%) e resultados experimentais revelam que para valores elevados de UR a dessecação ocorre mais lentamente; possivelmente, nessa época o risco de infecção seja maior. Além disso sabe-se que na região a população de $T$. infestans (ninfas de III, IV e, V e adultos) atinge o pico máximo, também na época chuvosa, o que aumentaria mais ainda o risco de infecção ${ }^{8}$. Trabalho publicado na década de $50^{4}$, relata a ocorrência de cerca de 300 casos agudos da doença de Chagas na regiào de Bambui, observou-se que $70 \%$ dos casos ocorreram entre os meses de outubro e março correspondente à época das chuvas e temperatura elevada. No entanto, uma análise de 76 casos de Chagas agudos observados em São Felipe, Bahia, não mostrou uma alta prevalência da fase aguda na época chuvosa ( $V$ Macêdo: comunicaçào pessoal). Mas, ocorre que, em São Felipe a umidade relativa é alta durante o ano inteiro e não somente na época chuvosa, o que nāo permite conclusões definitivas.

Uma observação da sazonalidade de casos agudos em Mambai antes do controle em 1980 não foi possivel porque poucos casos foram detectados no periodo de 1974-1980. Dados sobre 34 casos de Chagas agudo observados no Hospital Presidente Médici nos últimos cinco anos, também não mostraram nenhuma sazonalidade ( $\mathrm{C}$ Castro: comunicação pessoal). Esses dados também são pouco conclusivos porque os pacientes atendidos provèm de diversas regiōes, o que não nos permite um controle climatológico adequado.

Esta falha, relativa, de ligar época de chuva com ocorrência de Chagas agudo não surpreende muito porque, como já foi discutido anteriormente ${ }^{5}$, a desse- 
Soares VA, Marsden PD, Johnson C. Efeito da dessecação das fezes de triatomíneos na sobrevivência de formas metaciclicas de Trypanosoma cruzi. Revista da Sociedade Brasileira de Medicina Tropical 19: 233-238, Out-Dez, 1986.

cação é apenas um dos fatores dentro de um complexo muito grande de condições determinando a transmissão.

\section{$S U M M A R Y$}

We studied the rate of dessication of bug faeces at room temperature with different relative humidities and at the mean temperature of the human skin $\left(33^{\circ} \mathrm{C}\right)$.

The time necessary to evaporate the water present in bug faeces was inversely proportional to the atmosphere saturation deficit and was accelerated at higher temperatures.

We studied the motility of faecal flagellates on direct microscopy and infectivity of the same after the introduction of the faeces in the peritoneal cavity of mice.

At low humidities, both motility and infectivity were lost within 30 minutes, at high humidities these parameters were preserved up to 30 minutes at $33^{\circ} \mathrm{C}$. $100 \%$ of mice were infected after 15 minutes, but only $3.3 \%$ after 30 minutes exposure at this temperature.

Ambiental conditions of the interior of a house in Mambai varied greatly over a year of observation. However they were often similar to those of our laboratory experiments.

Key words: Dessication. Skin microclimate. Chagas' disease.

\section{REFERÊNCIAS BIBLIOGRÁFICAS}

1. Alvarenga NJ, Marsden PD. Estudos sobre a persistência de infectividade do T. cruzi. I. Efeito da temperatura sobre a infectividade de flagelados da amostra Peru de $T$. cruzi obtidos de fezes de triatomíneos. Revista da Sociedade Brasileira de Medicina Tropical 9: 283-287, 1975.

2. Brener Z. Contribuição ao estudo da terapêutica experimental da doença de Chagas. Tese, Faculdade de Farmácia, Universidade Federal de Minas Gerais, Belo Horizonte, 1961.

3. Chagas C. American Trypanosomiasis: study of the parasite and the transmitting insect. Proceedings of the Institute of Medicine, Chicago 3: 220-242, 1921.

4. Dias E. Informações acerca de 300 casos de doença de Chagas com período inicial conhecido fichados no Centro de Estudo de Bambui. O Hospital 47: 647-653, 1955.

5. Marsden PD. The transmission of Trypanosoma cruzi infections to man and control. In: Human Ecology and Infections Disease. Croll, NA e Cross, JH. (eds) Academic Press, New York, 253-289 p, 1983.

6. Montheit JL. Principles of Enviromental Physics. Edward Arnold Ltd. London 241 p, 1975.

7. Noble WC, Somerville DA. Microbiology of Human Skin. WB Saunders Co Ltd. Philadelphia, 220p. 1979.

8. Schofield CJ. Density regulation of domestic population of T. infestans in Brazil. Transactions of the Royal Society of Tropical Medicine and Hygiene 74: 761-769, 1980.

9. Zeledon R, Alvarenga NJ, Schosinsky K. Ecology of Trypanosoma cruzi in the insect vector. Chagas Disease Symposium Proceedings Pan American Health Organization Scientific Publication 347, Washington, 1975. 